\title{
Planning for Canadian Digestive Disease Week 2003
}

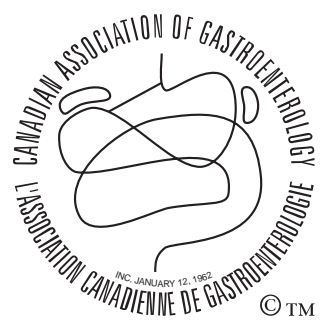

En français voir page 493

Desmond J Leddin MB FRCPC

CAG President Elect and Chair, Education Committee

Derek M McKay PhD

Chair, CAG Research Committee

C ranadian Digestive Disease Week (CDDW) 2003 will be held in Banff, Alberta from February 22 to 25, 2003. Plans are well advanced to develop a program that we know will be as attractive as the venue. As you begin to plan your itinerary for 2003, it is worth reflecting on what CDDW can offer that other meetings cannot. One can hardly argue that the American, European or other meetings throughout the world are lacking in scientific or educational quality.

There are a number of features that make this meeting especially worth attending. First, it is a Canadian meeting and addresses issues in gastroenterology from that perspective. For example, at last year's meeting in Montreal, Dr Flavio Habal from the University of Toronto, Ontario chaired a symposium entitled "Ambulatory Endoscopy in Canada". It is unlikely that you would get that kind of information in any other setting. Similarly, in 2003, we intend to focus on issues that are directly relevant to Canadian practice. Topics are selected in response to the annual Canadian Association of Gastroenterology (CAG) Needs Assessment from the membership.

Another advantage is that the CDDW meeting is a chance to meet and network with Canadian colleagues. Some of this is informal (for example at the opening reception or the gala dinner), and some, such as the CAG subcommittees, is more formal. It is an opportunity to meet, face-to-face, colleagues with whom you have been exchanging e-mails, faxes and telephone calls for the past 12 months.

The size of the meeting is also important. We have deliberately tried to keep the meeting from growing too large. While we encourage your participation and expect a good attendance in Banff, we do not wish to expand into the range of several thousand people, at which point the intimacy that characterizes CDDW would begin to disappear.

Another feature unique to CDDW is our ability to bring the subgroups of CAG, the Canadian Association for the Study of the Liver (CASL) and other organizations together for special events. The meeting will be preceded by a focused course for residents in training, which will be chaired by Dr Ron Bridges (University of Calgary, Alberta). Dr Jamie Gregor (University of Western Ontario, London, Ontario) will chair a course for more junior medical residents, with the aim of attracting them to the specialty of gastroenterology. Most importantly, the course for clinical gastroenterologists has been strengthened. In addition to the postgraduate course, which was brought back last year, there will be a number of excellent symposia. We are also considering breakfast sessions for the clinicians. This would be an opportunity to watch an international expert in the area work their way through a difficult case. For example, we are proposing in Banff to have some of our outstanding
Abbott Laboratories Ltd.
AstraZeneca Canada Inc.
Axcan Pharma Inc.
Janssen-Ortho Inc. 
experts in inflammatory bowel disease take small groups through the management of a patient with Crohn's disease who has failed to respond to therapy with methotrexate and azathioprine. CASL is in the process of developing an outstanding program in conjunction with CAG. We will be running joint symposia in Banff on topics that have been identified as being of major interest.

Last, but by no means least, the science program is being revised and should be finalized soon. Dr Derek McKay (McMaster University, Hamilton, Ontario), the chair of the CAG Research Committee, is committed to cementing the links between clinicians and scientists. At CDDW 2003, we look forward to two innovations. The first innovation is to develop scientific symposia that will entice, educate and stimulate the basic research scientist and the clinician/clinician scientist alike. Thus, scientific symposia will be designed and implemented with clinical applicability and relevance as an important consideration. The themes being developed are: pain, hypersensitivity and the enteric nervous system; the role of prostaglandins and other lipid mediators in health and disease; and components of the innate (antigen nonspecific) immune system and their role in digestive health. The symposia will comprise a blend of Canadian and international speakers, such as Professor Kim E Barrett, who will also present the prestigious RD McKenna Memorial Lecture. The second innovation being considered is a workshop and a 'careers evening' to address issues pertinent to the developing careers of our trainees how to write a good grant, academic verses pharmaceutical opportunities, and approaching a departmental chairman; these are some of the topics that will be covered. Finally, we wish to optimize the poster sessions, where the bulk of the basic and clinical science data are presented. The poster sessions are an excellent opportunity for networking, forming new collaborations and demonstrating to the trainees how important their contributions to gastroenterological research are.

We have no doubt that CDDW 2003 will be as good, or better, than the best international meetings, with a flavour that is known only to residents of Canada. Accordingly, we look forward to seeing you in Banff - mark your calendars now. 


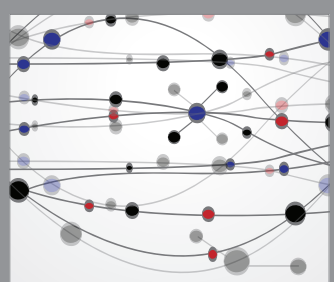

The Scientific World Journal
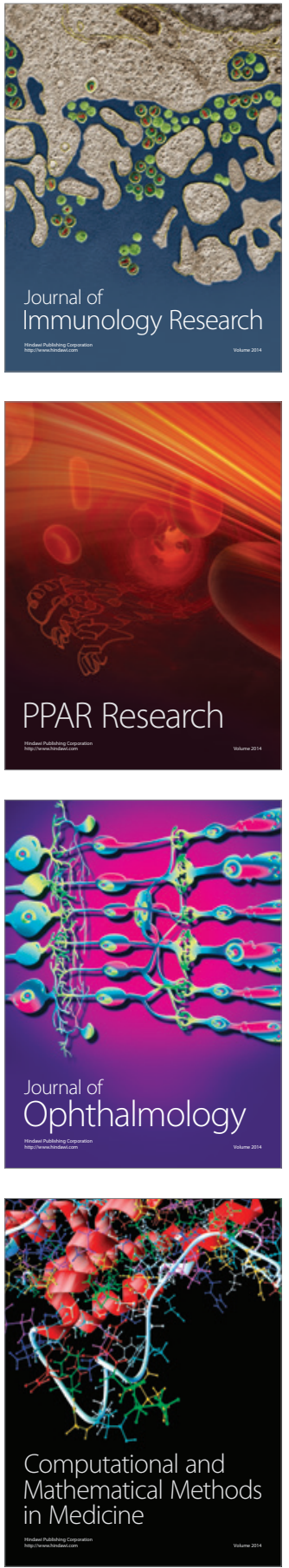

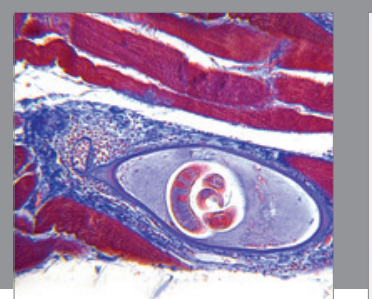

Gastroenterology Research and Practice

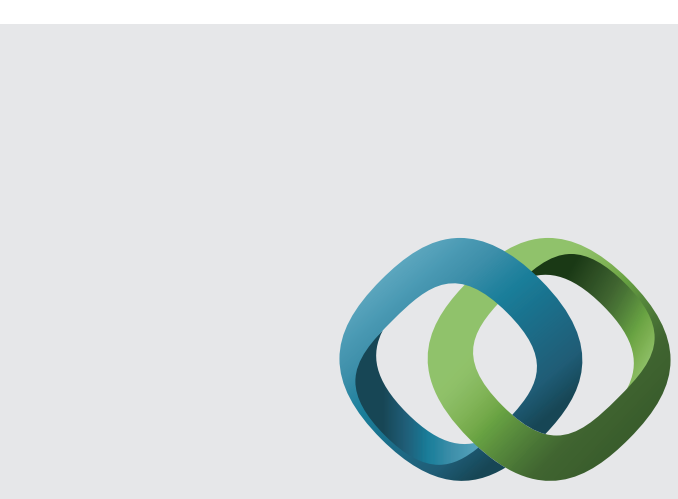

\section{Hindawi}

Submit your manuscripts at

http://www.hindawi.com
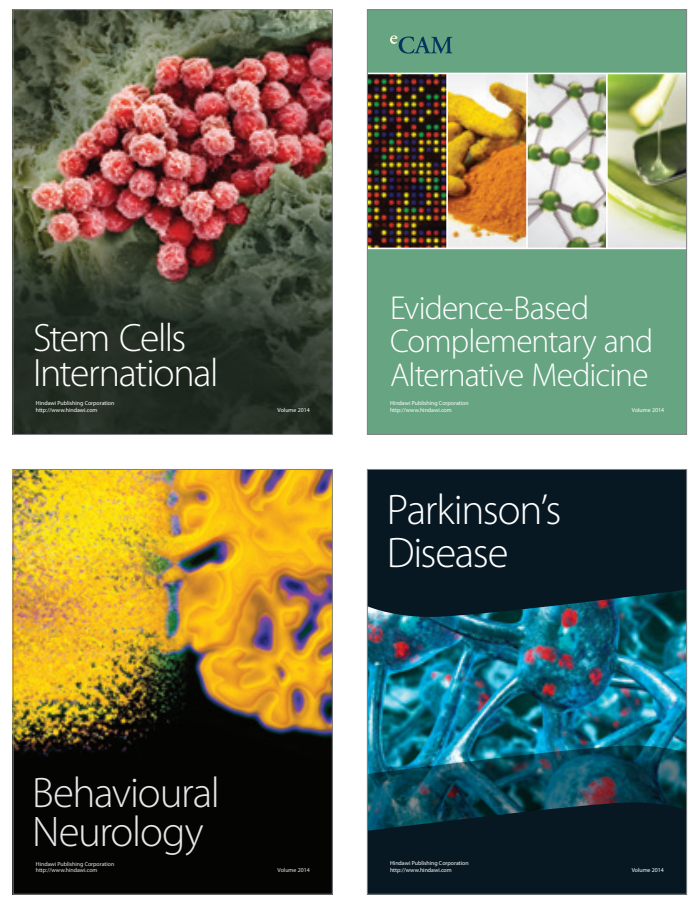
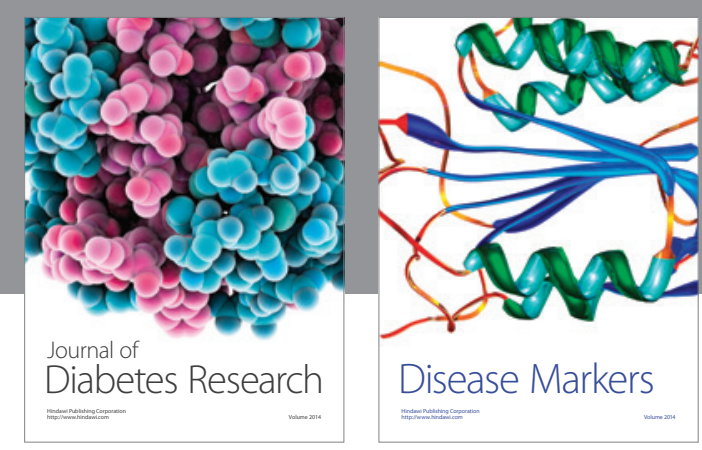

Disease Markers
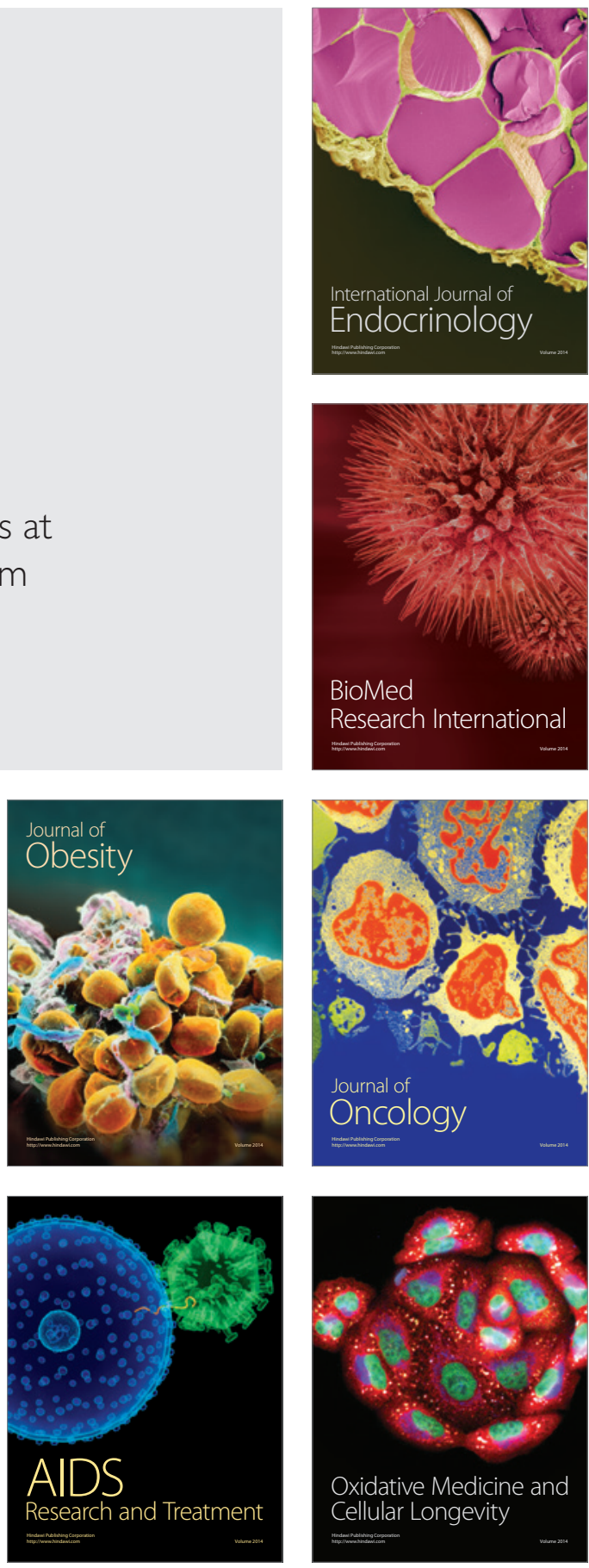